\title{
The design of an efficient class E-LCCL capacitive power transfer system through frequency tuning method
}

\author{
Khairul Kamarudin Hasan ${ }^{1}$, Shakir Saat ${ }^{2}$, Yusmarnita Yusop ${ }^{3}$, \\ Huzaimah Husin ${ }^{4}$, Nor Diyana Md Sin ${ }^{5}$ \\ 1,5Faculty of Electrical Engineering, Universiti Teknologi Mara, Cawangan Johor, \\ Kampus Pasir Gudang, Johor, Malaysia \\ 1,2,3,4Faculty of Electronic and Computer Engineering, Universiti Teknikal Malaysia, Melaka, Malaysia \\ ${ }^{2}$ School of Business and Social Sciences, Albukhary International University, Kedah Darul Aman, Malaysia
}

\begin{tabular}{|c|c|}
\hline Article Info & ABSTRACT \\
\hline & \multirow{9}{*}{$\begin{array}{l}\text { In this work, the optimum zero voltage switching (ZVS) of Class E-LCCL } \\
\text { capacitive power transfer (CPT) was determined via frequency tuning } \\
\text { method. Through this an efficient system can be guanranteed although there } \\
\text { is a change in the capacitive plates distance. This study used a Class-E LCCL } \\
\text { inverter, as it can operate at a high alternate current frequency, besides } \\
\text { producing low switching losses and minimal power losses. Specifically, this } \\
\text { study conducted simulations and experiments to analyse the performance of } \\
\text { an LCCL CPT System at } 1 \mathrm{MHz} \text { operating frequency and } 24 \mathrm{~V} \mathrm{DC} \mathrm{supply} \\
\text { voltage. Using an air gap distance of } 0.1 \mathrm{~cm} \text {, the designed CPT system } \\
\text { prototype successfully achieved an output power of } 10 \mathrm{~W} \text { and an efficiency of } \\
95.45 \% \text {. This study also found that by tuning the resonant frequency of the } \\
\text { Class E-LCCL system, the optimum ZVS can be obtained although capacitive } \\
\text { plate distance was varied from } 1-3 \mathrm{~cm} \text { via experimental. The results of this } \\
\text { study could benefit medical implant and portable device development, } \\
\text { consumer electronics, and environments that involve electrical hazards. }\end{array}$} \\
\hline Received Jan 21, 2020 & \\
\hline Revised Aug 21, 2020 & \\
\hline Accepted Sep 23, 2020 & \\
\hline Keywords: & \\
\hline Capacitive power transfer & \\
\hline Class E LCCL inverter & \\
\hline Frequency tuning & \\
\hline Zero voltage switching & \\
\hline
\end{tabular}

This is an open access article under the CC BY-SA license.

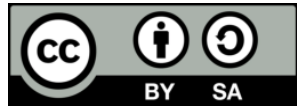

\section{Corresponding Author:}

Mohd Shakir Md Saat

School of Business and Social Sciences

Albukhary International University

Jalan Tun Abdul Razak 05200, Alor Setar, Kedah Darul Aman, Malaysia

Email: shakir.mdsaat@aiu.edu.my

\section{INTRODUCTION}

In this hyper-connected age, consumers demand less hassle when charging portable technology such as electric vehicles and mobile phones, and consider wires a major hindrance. Therefore, conventional methods involving wired charging are fast being replaced with wireless power transfer (WPT) technology, as illustrated in Figure 1. Currently, wireless power transfer (WPT) relies on power transmission that is not based on radiation, and mainly falls under three categories: acoustic energy transfer (AET), capacitive power transfer (CPT), and inductive power transfer (IPT), all of which are suitable for near-field applications [1-6]. These technologies have certain limitations such as sensitivity to frequency variations (e.g., AET) and sensitivity to metal barriers (e.g., IPT) [7-9]. Because of the weaknesses of AET and IPT; CPT, which transfers power via an electric field (i.e. without a wire contact at near field) $[10,11]$, was chosen as the current subject of study, with the main aim of reducing electromagnetic interference (EMI) and power losses [7, 8]. The primary disadvantage of using magnetic coupling in contactless power transfer methods is that it does not allow power to transmit through metal barriers. A CPT system containing a DC power supply, a resonant power converter, a rectifier, and a load is shown in Figure 2. 


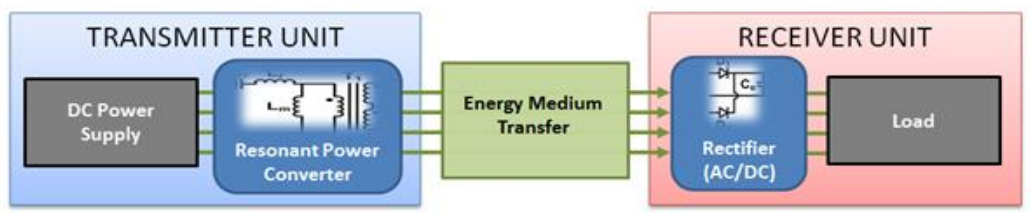

Figure 1. Wireless power transfer block diagram

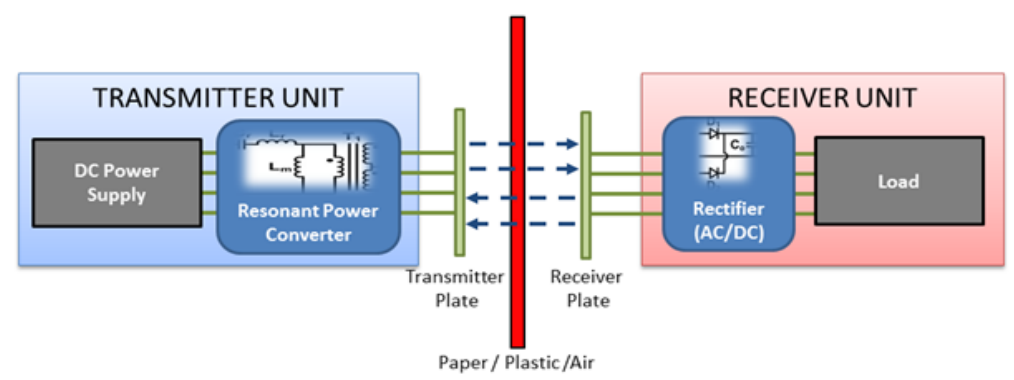

Figure 2. Capacitive power transfer block diagram

The CPT system uses capacitance coupling to transfer energy from other capacitor plates via an electrical insulator known as a dielectric. The dielectric is based on two capacitance concepts: i) mutual capacitance and ii) capacitive coupling. In the first, the capacitor plates are separated via electricity, usually by a material such as ceramic, plastic, waxed paper, or mica or a liquid gel. These plates are made of metal (conductive) and are connected in parallel $[12,13]$. In the second, energy is transferred within an electrical network (one plate to another plate) using a displacement current between circuits by inducing an electric field $[8,14,15]$. In the current CPT system, capacitive coupling was applied to transfer energy from one circuit to another circuit.

A CPT system normally transfers power wirelessly i.e. via an electric field [10, 11, 14-17]. Past studies have widely investigated the application of CPT in WPT such as in biomedical implants [18-21]. In one study, the dielectric material used successfully transferred 59-290 $\mathrm{mW}$ of energy through a beef shoulder that was $5 \mathrm{~mm}$ thick to the secondary implant side. The study used a capacitive link comprising two pairs of coated parallel plates aligned around the (beef) tissue to replace a series resonant converter in tank capacitors [19]. CPT technology was also applied for charging drone batteries [22], where one study successfully charged a drone with 3 battery cells at $50 \%$ efficiency and delivered $12 \mathrm{~W}$ of power. Elsewhere, CPT technology has also been used in industrial applications, eliminating the need for a mechanical slip ring and thus the traditional rotor power coupling technique in wound-field synchronous machines by replacing it with a capacitive non-contact power transfer technique [23]. Other successful works were done using multiple rotary plates for a CPT prototype with the results revealing more than $76 \%$ power transfer efficiency at $1 \mathrm{MHz}$ operating frequency, albeit at a $1 \mathrm{~mm}$ plate distance [24].

By considering all aspects significant to the CPT system, this research focuses more on analysing, optimising the functionality, and designing an effective CPT system with efficient wireless power transfer capabilities. Capacitance coupling is the transfer of energy within an electrical network (one plate to another plate) via the displacement current between circuits by inducing an electric field $[8,14,15]$. A Class E-LCCL inverter was used for the current circuit to produce the desired output power [25]. Two circuits-a Class E-LC topology circuit and an LC match circuit-are combined in this inverter. The main advantage of this circuit is that it can match the power requirement by converting the current impedance to the desired impedance [26].

All the studies mentioned above struggled to define the maximum power transfer in the capacitive plates based on the plate distance, for example, biomedical implants have a maximum transfer distance limited to around $5 \mathrm{~mm}$ between plates. In other applications, some researchers selected a maximum distance of around $1 \mathrm{~mm}$ to achieve maximum efficiency, by matching the impedance at the transfer unit to that of the receiver unit. In this study, a Class E-LCCL inverter was implemented for the capacitive power transfer (CPT) system to achieve high efficiency, to reduce the plate size, and to reduce the electric field emission during the transfer of energy from the transmitter to the receiver [25, 24]. In specific, in this paper, the distance of the capacitive plates was analysed by investigating the result of ZVS using a Class E-LCCL system by tuning the resonant frequency in real-time and by adjusting the distance of the capacitive plates from $1-7 \mathrm{~cm}$. 
There are four main sections in this paper. The analysis and design of the Class E-LCCL capacitive power transfer system are presented in section 2 together with the design specifications of the system and the simulation and experimental results. Section 3 presents the selected resonant frequency for the Class E-LCCL CPT system together with the simulation and experimental works to get the best ZVS. This section also discusses and analyses related ZVS and the output power of the circuit system designed. Finally, a summary of the findings is presented in section 4 .

\section{CLASS E-LCCL CPT SYSTEM}

Section 1 discussed the background of wireless power transfer (WPT) with an emphasis on CPT. In this section, an overview of the Class E-LCCL CPT System designed in this study is presented together with its design specifications and the results of simulation and experimental works. A Class E-LCCL inverter was used in the proposed circuit to produce the desired output power [25]. Two circuits-a Class E-LC topology circuit and an LC match circuit-were combined in this inverter. The main advantage of this circuit is that it can match the power requirement by converting the current impedance to the desired impedance. Figure 3 illustrates the Class E-LCCL system.

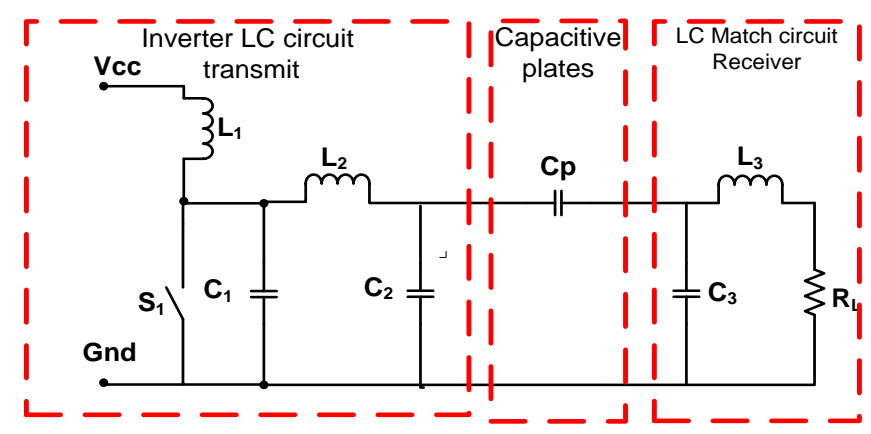

Figure 3. The class E-LCCL CPT system

It is assumed that all conditions for the Class-E inverter are satisfied and that the switch is perfect. Also, the power dissipated in the load resistor is assumed to be equivalent to the DC power provided by the bias DC source. Therefore, $10 \mathrm{~W}$ was chosen as the power delivered to the load while $24 \mathrm{~V}$ was selected as the input voltage, Vcc. All circuit component values were obtained using (1) and (2) [25].

The value of the capacitors:

$$
C_{1}=\frac{1}{33.22 \omega\left(\frac{\pi^{2}}{4}+1\right) \frac{\pi}{2}}, C_{P}=\frac{1}{2 \pi f\left[\frac{2633.62}{8.85-\sqrt{\frac{2633.62}{R_{L}}-1}}\right]}, C_{2}=\frac{1}{2 \pi f\left[R_{L} \sqrt{\frac{2633.62}{R_{L}}-1}\right]}, C_{3}=\frac{1}{2 f \omega\left[\frac{1316 R_{L}}{2 \pi f L_{3}}\right]}
$$

The value of the inductors:

$$
L_{1}=66.33\left(\frac{\pi^{2}}{4}-1\right) \frac{1}{f}, L_{2}=\frac{33.22 Q}{\omega}, L_{3}=\frac{\sqrt{1316 R_{L}-R_{L}^{2}}}{2 \pi f}
$$

The system efficiency was calculated as $100 \%$. This result was then checked against the simulation results and the experimental findings. Power input, Power output, and zero voltage switching (ZVS) were measured in MATLAB. Finally, the results of varying the capacitance plate distance from 1-7 cm were obtained. The variables that were calculated are listed in Table 1.

The experimental setup of the Class E-LCCL CPT system is shown in Figure 4. To ensure precise results are obtained (i.e. system efficiency, power output, power input, and ZVS measurements), the components used in this study used exactly matched or were similar to that of the simulation circuit. The simulation result and the experiment result were discussed in detail while considering a coupling capacitance plate distance, $\mathrm{Cp}$, of $0.1 \mathrm{~cm}$. Zero voltage switching (ZVS) is an important variable, as it ensures minimal power losses during switching in MOSFET [27]. 
Table 1 . The variables of the study

\begin{tabular}{ccc}
\hline Name of variable & Unit & Value \\
\hline Load resistance & $\mathrm{R}_{\mathrm{L}}$ & $50 \Omega$ \\
DC supply voltage & $\mathrm{V}_{\mathrm{cc}}$ & $24 \mathrm{~V}$ \\
Reactance capacitor value & $\mathrm{C}_{1}$ & $880 \mathrm{pF}$ \\
Transmit resonant capacitor & $\mathrm{C}_{2}$ & $475 \mathrm{pF}$ \\
Receiver impedance capacitor & $\mathrm{C}_{3}$ & $609 \mathrm{pF}$ \\
Coupling capacitor value & $\mathrm{C}_{\mathrm{P}}$ & $120.9 \mathrm{pF}$ \\
Choke inductor & $\mathrm{L}_{1}$ & $230 \mu \mathrm{H}$ \\
Reactance inductor value & $\mathrm{L}_{2}$ & $53 \mu \mathrm{H}$ \\
Receiver impedance inductor & $\mathrm{L}_{3}$ & $40 \mu \mathrm{H}$ \\
\hline
\end{tabular}

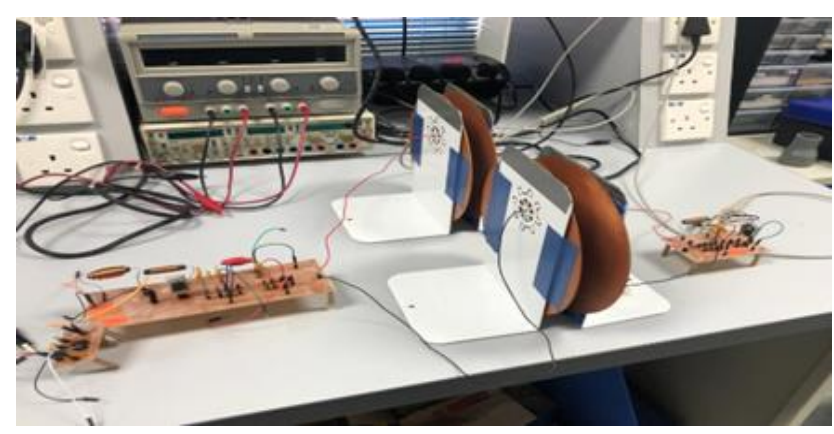

Figure 4. The CPT LCCL system experimental setup

Figure 5 shows the simulation results of ZVS, depicting a VDS $=87 \mathrm{~V}$ and smooth, efficient switching while Figure 6 shows the ZVS experimental results with a VDS=107 V, which is still considered acceptable. Theoretically, both values of VDS (experimental and simulation) are good because both are higher than Vcc by 3- to 4-fold. Figure 7 to Figure 10 show the result of the experimental and simulated power input and output as well as the system efficiency.

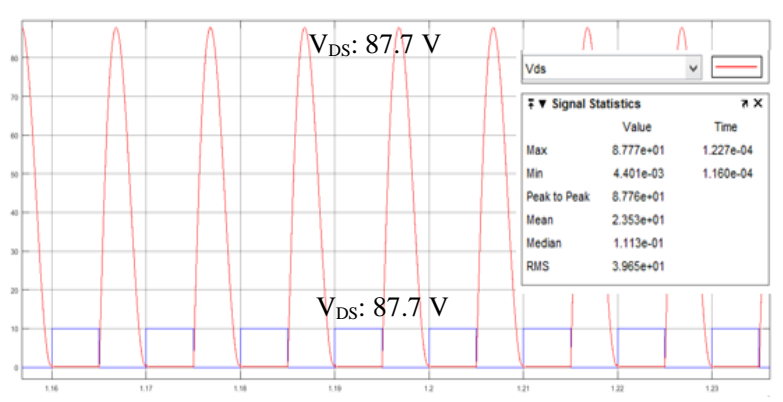

Figure 5. ZVS simulation result of the Class E-LCCL CPT SYSTEM

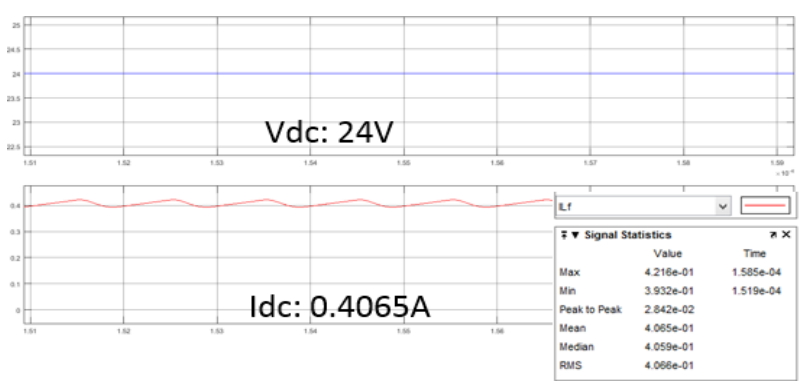

Figure 7. Class E-LCCL CPT system input voltage and input current simulation result

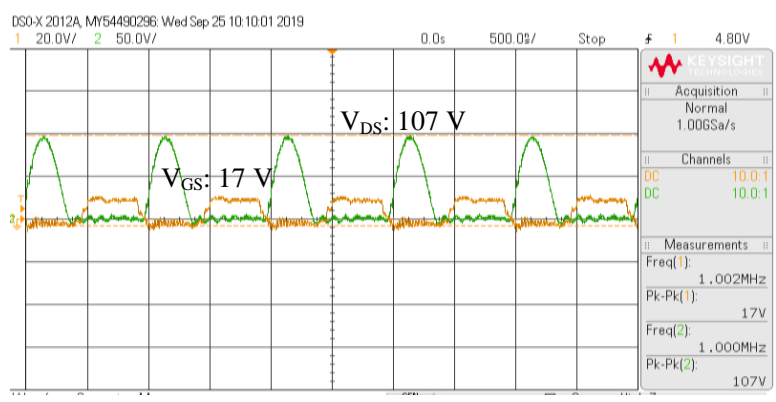

Figure 6. ZVS experimental result of the Class E-LCCL CPT system

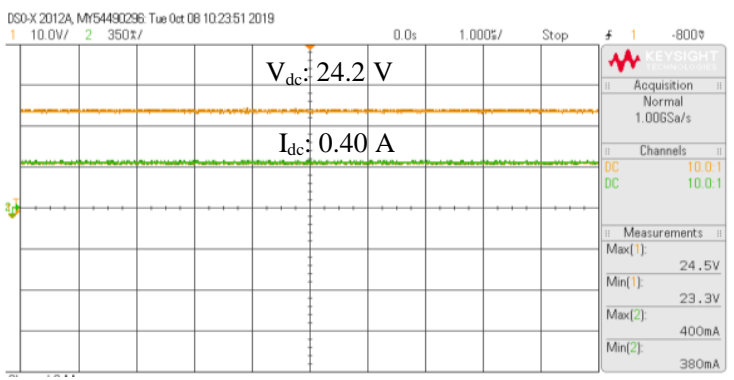

Figure 8. Class E-LCCL CPT system output voltage and output current simulation result 




Figure 9. Class E-LCCL CPT system input voltage and input current experimental result

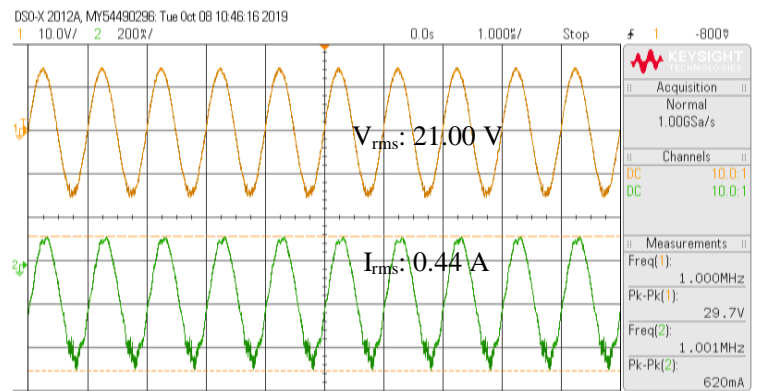

Figure 10. Class E-LCCL CPT system output voltage and output current experimental result

As shown in (3) presents an equation to calculate the system efficiency based on the power input and output obtained and as presented in Figures 6 to 9:

$$
\% n=\frac{V o(r m s) * I o(r m s)}{\operatorname{Vin}(d c) * \operatorname{Iin}(d c)}
$$

Table 2 lists the LCCL CPT system simulated and experimental efficiency, which are $97.96 \%$ and $95.45 \%$, respectively. This result is based on the following conditions: the coupling capacitance plate distance was set to $1 \mathrm{~mm}$ and the load was $50 \Omega$, while the power was $10 \mathrm{~W}$; both results indicate the system's high efficiency in transferring power.

Table 2. System efficiency results

\begin{tabular}{cccc}
\hline Variable & Variable Unit & Simulation Result & Experimental Result \\
\hline Input Current $(\mathrm{dc})$ & $\mathrm{I}_{\text {in }}(\mathrm{dc})$ & $0.41 \mathrm{~A}$ & $0.40 \mathrm{~A}$ \\
Output Current $(\mathrm{rms})$ & $\mathrm{I}_{\mathrm{o}}(\mathrm{rms})$ & $0.44 \mathrm{~A}$ & $0.44 \mathrm{~A}$ \\
Input Voltage $(\mathrm{dc})$ & $\mathrm{V}_{\text {in }}(\mathrm{dc})$ & $24.00 \mathrm{~V}$ & $24.20 \mathrm{~V}$ \\
Output Voltage $(\mathrm{rms})$ & $\mathrm{V}_{\mathrm{o}}(\mathrm{rms})$ & $21.86 \mathrm{~V}$ & $21.00 \mathrm{~V}$ \\
Efficiency & $\% \mathrm{n}$ & $97.77 \%$ & $95.45 \%$ \\
\hline
\end{tabular}

Next section of this paper is to investigate the performance of CPT system when the distance of cpacitive plate is no longer $0.1 \mathrm{~cm}$. In this case, we investigate the condition of ZVS when the coupling plates distance are varied from $1-7 \mathrm{~cm}$. Then the frequency tunung approach is proposed to get the optimum ZVS condition despite of the coupling capacitance plate's distance.

\section{OPTIMUM ZVS DESIGN}

In Section 2, the Class E-LCCL CPT system at resonant frequency, operating at a $1 \mathrm{MHz}$ frequency with $97.96 \%$ and $95.45 \%$ efficiency, based on the results of the simulation and experimental works, respectively, was analysed at $1 \mathrm{~mm}$ coupling gap distance. This section focuses on analysing the adjustment in the operating resonant frequency to select the best ZVS via calculation when the coupling plate's distance change. Table 3 shows the values of the variables when the distance between the coupling capacitance plates was varied from $1-7 \mathrm{~cm}$.

Table 3. Variable values of the class E-LCCL CPT system when the plate distance

\begin{tabular}{cccccccc}
\multicolumn{7}{c}{ was varied from $1 \mathrm{~cm}$ to $7 \mathrm{~cm}$} \\
\hline Distance & $1 \mathrm{~cm}$ & $2 \mathrm{~cm}$ & $3 \mathrm{~cm}$ & $4 \mathrm{~cm}$ & $5 \mathrm{~cm}$ & $6 \mathrm{~cm}$ & $7 \mathrm{~cm}$ \\
\hline $\mathrm{V}_{\text {in }}$ & 24.2 & 24 & 24 & 24.2 & 24.1 & 24.1 & 24.1 \\
$\mathrm{I}_{\text {in }}$ & 0.45 & 0.55 & 0.64 & 0.7 & 0.71 & 0.73 & 0.75 \\
$\mathrm{~V}_{\mathrm{o}}$ & 21.21 & 15.06 & 13.65 & 9.26 & 5.65 & 5.23 & 4.6 \\
$\mathrm{I}_{\mathrm{o}}$ & 0.37 & 0.26 & 0.23 & 0.2 & 0.12 & 0.11 & 0.1 \\
$\mathrm{P}_{\text {in }}$ & 10.89 & 13.2 & 15.36 & 16.94 & 17.111 & 17.593 & 18.075 \\
$\mathrm{P}_{\text {out }}$ & 7.8477 & 3.9156 & 3.1395 & 1.852 & 0.678 & 0.5753 & 0.46 \\
$\%$ n & 72.06 & 29.66 & 20.44 & 10.93 & 3.96 & 3.27 & 2.54 \\
\hline
\end{tabular}


The result shows that the change in capacitive plate distance could reduce emission field energy, as it is affected by total impedance, which will decrease, with an especially drastic reduction in efficiency when the plate distance was varied from $1-3 \mathrm{~cm}$. Figure 11 shows the system efficiency when the coupling capacitive plates were varied from $1-7 \mathrm{~cm}$.

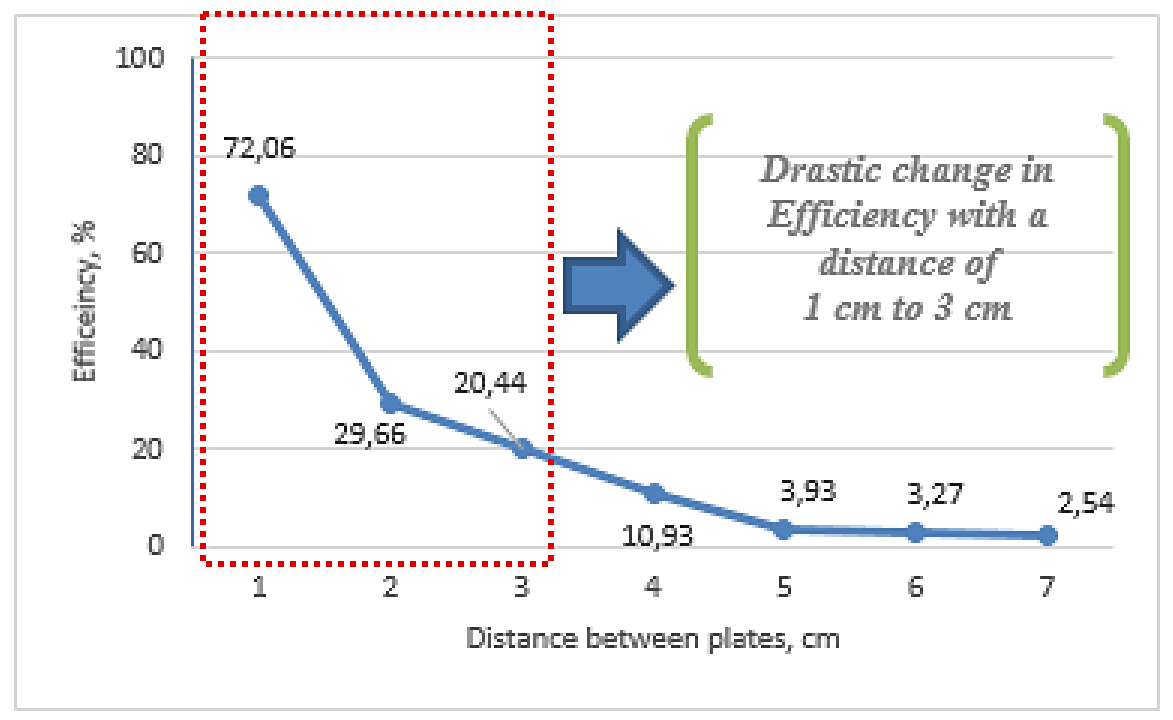

Figure 11. Graph of system efficiency vs. varying the distance of the capacitive plates from $1 \mathrm{~cm}$ to $7 \mathrm{~cm}$

The result above does not exactly represent the switching of ZVS, as ZVS is affected by the change in the resonant frequency of the operating system.

The resonant frequency must, therefore, be selected from (4):

$$
C_{e q}=\frac{C_{1} C_{S}}{C_{1}+C_{S}}, f_{01}=\frac{1}{2 \pi \sqrt{L C_{s}}}, f_{02}=\frac{1}{2 \pi \sqrt{L C_{e q}}}, f_{0}=\frac{f_{02}-f_{01}}{2}
$$

Table 4 shows the result of the calculations for the new resonant frequencies of the system while varying the capacitive plate distance from $1-3 \mathrm{~cm}$. The total capacitor series value and total equivalent capacitor value had to be changed due to the change in the capacitive plate value, which is $34.39 \mathrm{pF}$ at $1 \mathrm{~cm}$, $18.4 \mathrm{pF}$ at $2 \mathrm{~cm}$, and $14 \mathrm{pF}$ at $\mathrm{cm}$.

Table 4. Difference in variables as the plate distance was varied from $1 \mathrm{~cm}$ to $3 \mathrm{~cm}$

\begin{tabular}{lcccc}
\hline \multicolumn{1}{c}{ Variable } & Unit & $1 \mathrm{~cm}$ & $2 \mathrm{~cm}$ & $3 \mathrm{~cm}$ \\
\hline Reactance inductor value & $\mathrm{L}$ & $53 \mathrm{uH}$ & $53 \mathrm{uH}$ & $53 \mathrm{uH}$ \\
Reactance capacitor value & $\mathrm{C}_{1}$ & $880 \mathrm{pF}$ & $880 \mathrm{pF}$ & $880 \mathrm{pF}$ \\
Total capacitor series value & $\mathbf{C}_{\mathbf{S}}$ & $\mathbf{5 0 9 . 5 5} \mathbf{~} \mathbf{F}$ & $\mathbf{4 9 3 . 4 2} \mathbf{~ p F}$ & $\mathbf{4 8 9 . 0 1} \mathbf{~ p F}$ \\
Total equivalent capacitor value & $\mathbf{C}_{\text {eq }}$ & $\mathbf{3 2 2 . 7} \mathbf{~ F F}$ & $\mathbf{3 1 6 . 1 5} \mathbf{~ F F}$ & $\mathbf{3 1 4 . 3 3} \mathbf{~ F F}$ \\
Low resonant frequency & $\mathrm{f}_{01}$ & $0.968 \mathrm{MHz}$ & $0.984 \mathrm{MHz}$ & $0.989 \mathrm{MHz}$ \\
High resonant frequency & $\mathrm{f}_{02}$ & $1.217 \mathrm{MHz}$ & $1.230 \mathrm{MHz}$ & $1.233 \mathrm{MHz}$ \\
Resonant Frequency of the system & $\mathrm{f}_{0}$ & $1.093 \mathrm{MHz}$ & $1.107 \mathrm{MHz}$ & $1.110 \mathrm{MHz}$ \\
\hline
\end{tabular}

Thus, the measurement values are relevant for the calculation of the Class E-LCCL CPT system resonant frequency when the distance plates were varied. The ZVS, output voltage, and output current were measured using a digital storage oscilloscope (Agilent Technologies). Figure 12 shows the result of ZVS, and the change in the output voltage and the output current when the distance between the capacitive plates, fixed at $1 \mathrm{MHz}$ resonant frequency, was set to $1 \mathrm{~cm}, 2 \mathrm{~cm}$, and $3 \mathrm{~cm}$. The result shows the ZVS showing a gap during switching and the output voltage and the output current dropping with this change in distance. Figure 13 shows the result of the ZVS, the output voltage, and the output current when the resonant frequency was varied, as per Table 4. 


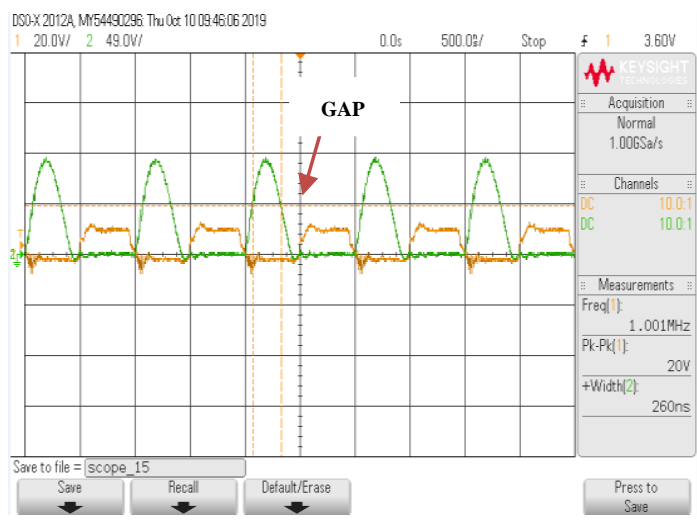

(a)

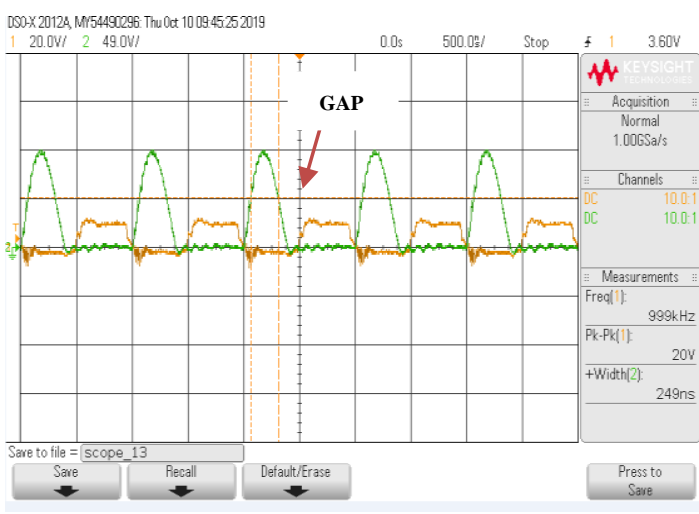

(c)

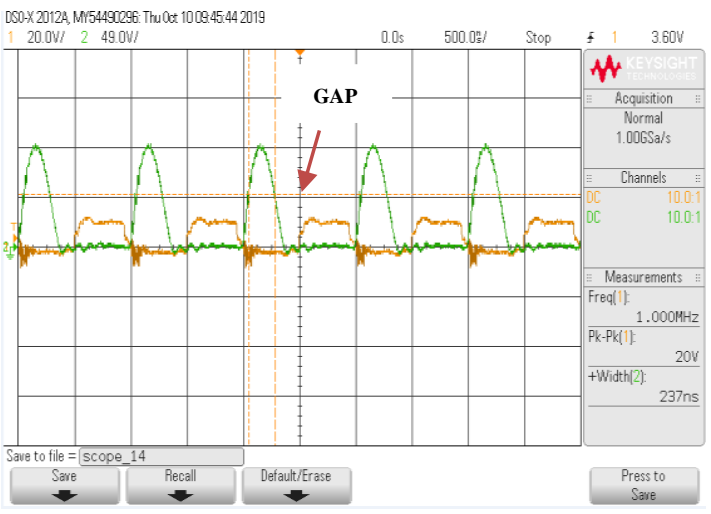

(e)

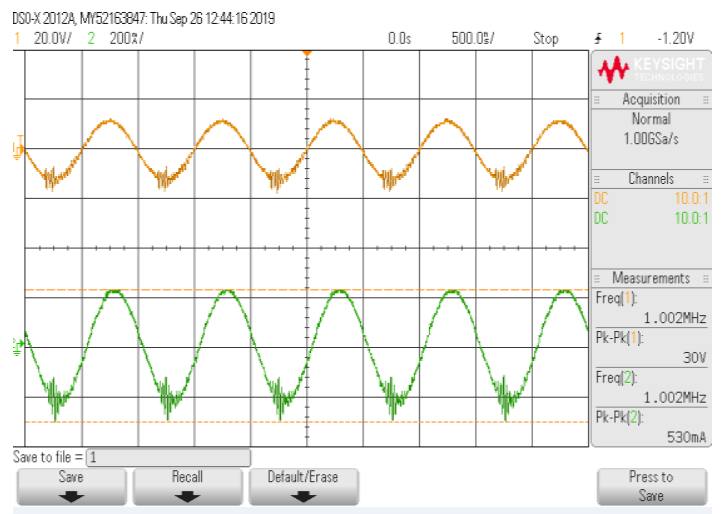

(b)

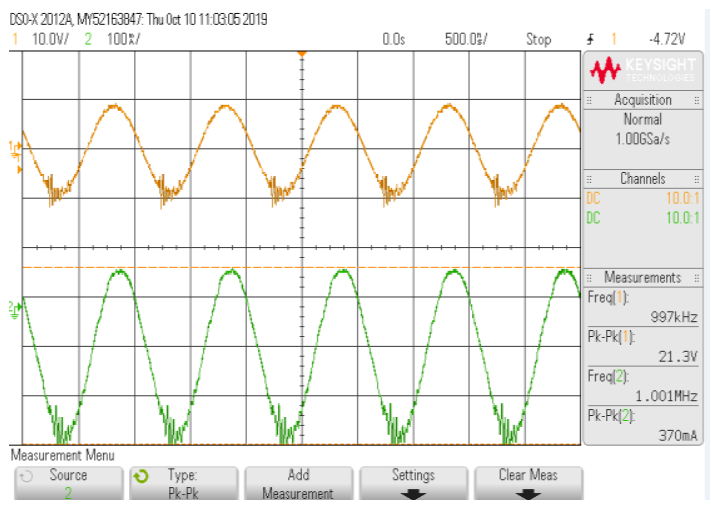

(d)

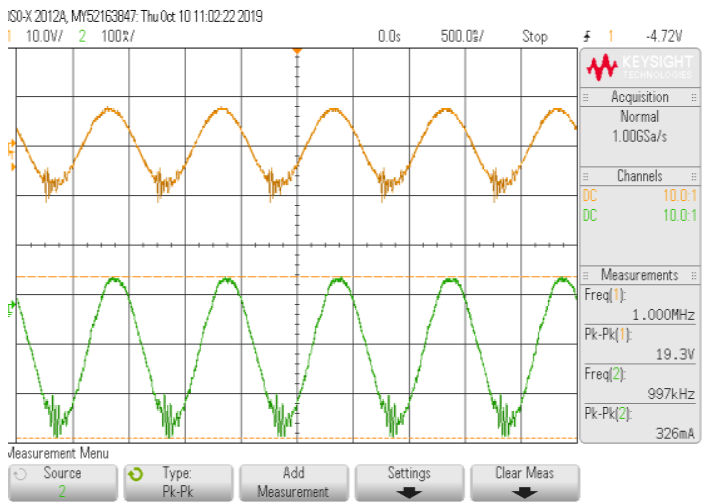

(f)

Figure 12. ZVS, ouput voltage, and output current at a fixed $1 \mathrm{MHz}$ resonant frequency; (a) ZVS at $1 \mathrm{~cm}$, (b) output at $1 \mathrm{~cm}$, (c) ZVS at $2 \mathrm{~cm}$, (d) output at $2 \mathrm{~cm}$, (e) ZVS at $3 \mathrm{~cm}$, (f) output at $3 \mathrm{~cm}$

The above result shows that the best ZVS condition was achieved with no gap during switching, with an operating resonant frequency between the bandwidth frequencies of f01 and f02. Otherwise, the results of the output voltage and output current would reduce drastically when the frequency was increased. Increasing the resonant frequency of the Class E-LCCL CPT affected the output voltage and the output current. Both parameters are related to the delivery of power to the load. Based on the analysis conducted, a change in the power output was obtained when the resonant frequency was changed because the total impedance of the Class E-LCCL CPT system also changed. After the calculation was done manually for a plate distance of $1 \mathrm{~mm}$, the total impedance was found to be $57.94+\mathrm{j} 198.42 \mathrm{Ohm}$ prefers of inductance impedance, XL. When the resonant frequency was increased, the total inductance impedance increased and caused the power output to drop. The power output is inversely proportional to the overall impedance of the Class E-LCCl CPT system. 


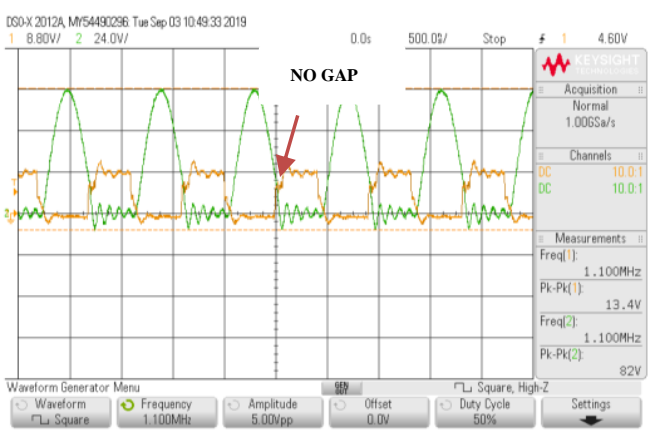

(a)

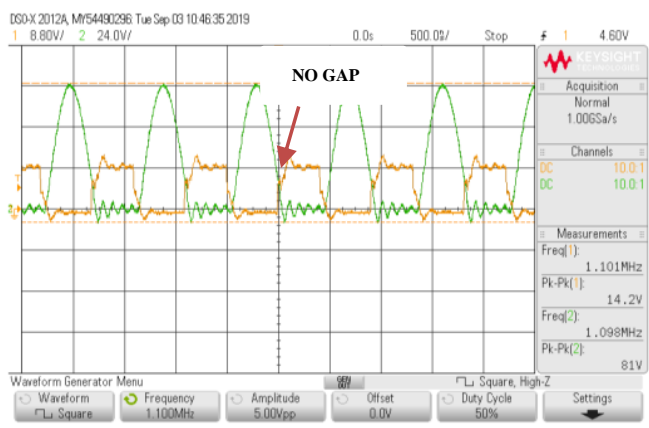

(c)

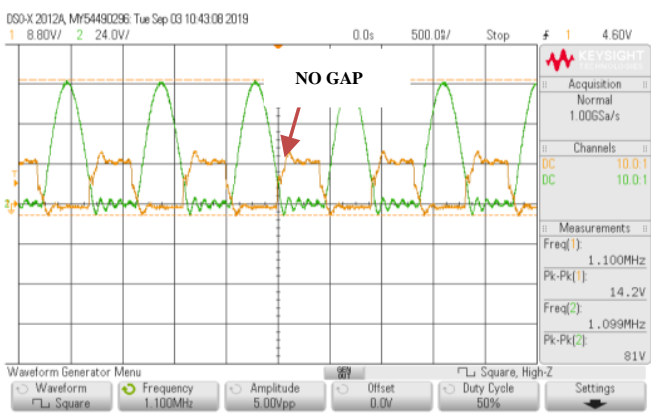

(e)

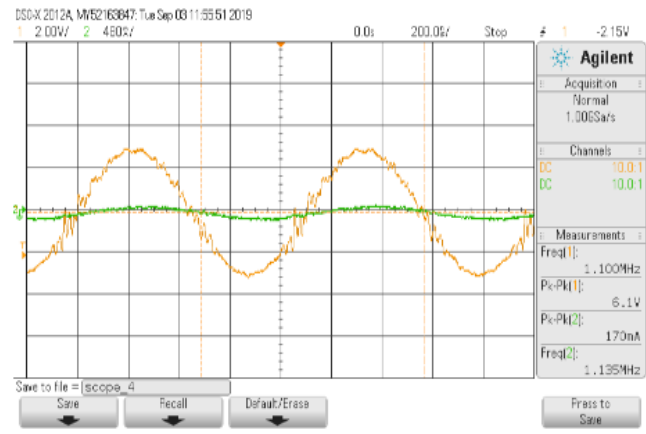

(b)

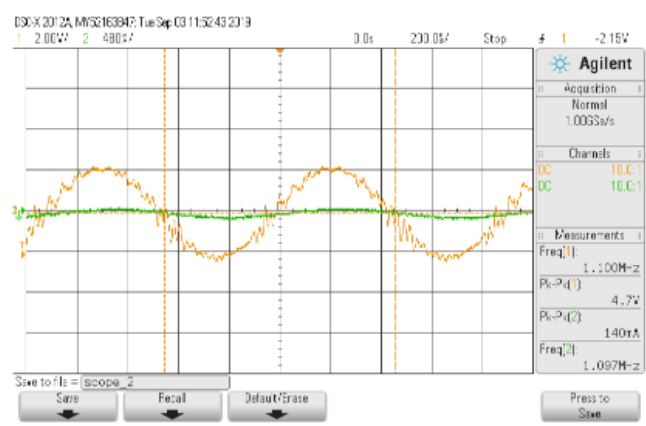

(d)

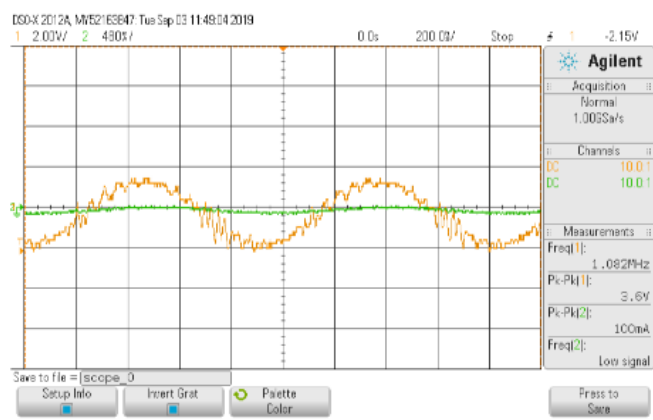

(f)

Figure 13. ZVS, ouput voltage, and output current at varying resonant frequencies; (a) ZVS at $1 \mathrm{~cm}$, (b) output at $1 \mathrm{~cm}$, (c) ZVS at $2 \mathrm{~cm}$, (d) output at $2 \mathrm{~cm}$, (e) ZVS at $3 \mathrm{~cm}$, (f) output at $3 \mathrm{~cm}$

\section{CONCLUSION AND FUTURE WORK}

In this study, a Class E-LCCL CPT System was successfully designed, operating at $1 \mathrm{MHz}$ resonant frequency, and achieving $97.96 \%$ and $95.45 \%$ simulated and experimental efficiencies, respectively at $0.1 \mathrm{~cm}$ coupling gap distance. It was found that the efficiency of the overall CPT system was affected by power losses in the rectifier, the transmitter unit and the variation in the capacitive coupling distance. This study also identified the optimum ZVS can be achieved when the resonant frequency of the system is varied accordingly based on the distance changed. This study primarily aimed to reduce the power loss in the transmitter to enhance the CPT system efficiencyand it has been successfully delivered. It is recommended that future works focus on designing the mechanism to control thr frequency automatically when there is a change in distance. The findings of this study will greatly benefit wireless technology applications, especially in the medical field.

\section{ACKNOWLEDGEMENTS}

Sincerely to express the appreciation to Universiti Teknologi MARA (UiTM), Universiti Teknikal Malaysia Melaka (UTeM) and Albukhary International University for professional support. 


\section{REFERENCES}

[1] T. Zaid, S. Saat, Y. Yusop, and N. Jamal, "Contactless energy transfer using acoustic approach-A review," 2014 International Conference on Computer, Communications, and Control Technology (I4CT), Langkawi, 2014, pp. 376-381.

[2] M. P. Kazmierkowski and A. J. Moradewicz, "Contactless energy transfer (CET) systems-A review," 2012 15th International Power Electronics and Motion Control Conference (EPE/PEMC), Novi Sad, 2012, pp. 31-36,

[3] D. Rozario, N. A. Azeez, and S. S. Williamson, "A modified resonant converter for wireless capacitive power transfer systems used in battery charging applications," 2016 IEEE Transportation Electrification Conference and Expo (ITEC), Dearborn, MI, 2016.

[4] K. D. Papastergiou and D. Ewen Macpherson, "An airborne radar power supply with contactless transfer of energyPart I: Rotating transformer," IEEE Transactions on Industrial Electronics, vol. 54, no. 5, pp. 2874-2884, 2007.

[5] A. S. Rekhi, B. T. Khuri-Yakub, and A. Arbabian, "Wireless Power Transfer to Millimeter-Sized Nodes Using Airborne Ultrasound," IEEE Transactions on Ultrasonics, Ferroelectrics, and Frequency Control, vol. 64, no. 10, pp. 1526-1541, 2017.

[6] C. Mi, "High efficiency wireless power transfer for ev charging and other applications," 2017 IEEE Energy Conversion Congress and Exposition (ECCE), Cincinnati, OH, 2017, pp. 1-184.

[7] H. Husin, S. Saat, Y. Yusop, and S. K. Nguang, "Development of $416 \mathrm{kHz}$ PZT driver for acoustics energy transfer applications," 2016 IEEE 12th International Colloquium on Signal Processing \& Its Applications (CSPA), Malacca City, 2016, pp. 88-93,

[8] Z. Zhang, H. Pang, A. Georgiadis, and C. Cecati, "Wireless Power Transfer-An Overview," IEEE Transactions on Industrial Electronics, vol. 66, no. 2, pp. 1044-1058, 2019.

[9] J. Dai and D. C. Ludois, "Wireless electric vehicle charging via capacitive power transfer through a conformal bumper," 2015 IEEE Applied Power Electronics Conference and Exposition (APEC), Charlotte, NC, 2015, 2015, pp. 3307-3313.

[10] M. Kline, I. Izyumin, B. Boser, and S. Sanders, "Capacitive power transfer for contactless charging," 2011 Twenty-Sixth Annual IEEE Applied Power Electronics Conference and Exposition (APEC), Fort Worth, TX, 2011, pp. 1398-1404.

[11] C. Liu and A. P. Hu, "Steady state analysis of a capacitively coupled contactless power transfer system," in 2009 IEEE Energy Conversion Congress and Exposition, San Jose, CA, 2009, pp. 3233-3238.

[12] J. R. Miller, "Engineering electrochemical capacitor applications," Journal of Power Sources, vol. 326, pp. 726-735, 2016.

[13] J. R. Miller, "Perspective on electrochemical capacitor energy storage," Applied Surface Science, vol. 460, pp. 3-7, 2018.

[14] L. J. Zou and A. P. Hu, "A Contactless Single-Wire CPT (Capacitive Power Transfer) Power Supply for Driving a Variable Message Sign,” 2018 IEEE PELS Workshop on Emerging Technologies: Wireless Power Transfer (Wow), Montréal, QC, 2018, pp. 1-5.

[15] K. Kamarudin, S. Saat, and Y. Yusmarnita, "Analysis and design of wireless power transfer: A capacitive based method," 2014 IEEE Symposium on Industrial Electronics \& Applications (ISIEA), Kota Kinabalu, 2014, pp. 136-141.

[16] K. Kh, Shakir Saat, Y. Yusmarnita, and N. Jamal, "Analysis and Design of Wireless Power Transfer : A Capacitive Based Method for Low Power Applications," WSEAS Transactions on Circuits and Systems, vol. 14, pp. 221-229, 2015.

[17] K. Kamarudin, M. S. Ramli, A. W. SitiSufiah, N. F. Razali, and S. A. Nordin, "Designation and Investigate of a Full-Wave Controller Rectifier (FWCR) for Effect Source Inductance for Full Wave Rectifier," MATEC Web of Conferences, vol. 70, 2016, pp. 1-4.

[18] M. Z. Bin Mustapa, S. Saat, Y. Yusof, and M. M. Shaari, "Capacitive power transfer in biomedical implantable device: a review," International Journal of Power Electronics and Drive Systems (IJPEDS), vol. 10, no. 2, pp. 935-942, 2019.

[19] R. Erfani, F. Marefat, A. M. Sodagar, and P. Mohseni, "Transcutaneous capacitive wireless power transfer (C-WPT) for biomedical implants," 2017 IEEE International Symposium on Circuits and Systems (ISCAS), Baltimore, MD, 2017, pp. 1-4.

[20] R. Sedehi, D. Budgett, A. P. Hu, and D. McCormick, "Effects of Conductive Tissue on Capacitive Wireless Power Transfer," 2018 IEEE PELS Workshop on Emerging Technologies: Wireless Power Transfer (Wow), Montréal, QC, 2018, pp. 1-5.

[21] Z. Mustapa, S. Saat, and Y. Yusof, "A new design of capacitive power transfer based on hybrid approach for biomedical implantable device," International Journal of Electrical and Computer Engineering (IJECE), vol. 9, no. 4, pp. 2365-2376, 2019.

[22] T. M. Mostafa, A. Muharam, and R. Hattori, "Wireless battery charging system for drones via capacitive power transfer," 2017 IEEE PELS Workshop on Emerging Technologies: Wireless Power Transfer (WoW), Chongqing, 2017, pp. 1-6.

[23] D. C. Ludois, K. Hanson, and J. K. Reed, "Capacitive power transfer for slip ring replacement in wound field synchronous machines," 2011 IEEE Energy Conversion Congress and Exposition, Phoenix, AZ, 2011, pp. 1664-1669,.

[24] Y. Yusop, S. Saat, Z. Ghani, H. Husin, M. K. Adie, and S. Kiong, "A Cascaded Boost-Class-E for Rotary Capacitive Power Transfer System,” The Journal of Engineering, vol. 2019, no. 17, pp. 3742-3748, 2019.

[25] Y. Yusop, H. Husin, S. Saat, S. K. Nguang, and Z. Ghani, "Class-E LCCL for capacitive power transfer system," 2016 IEEE International Conference on Power and Energy (PECon), Melaka, 2016, pp. 428-433.

[26] Y. Yusop, S. Saat, Z. Ghani, H. Husin, and S. K. Nguang, "Capacitive power transfer with impedance matching network," 2016 IEEE 12th International Colloquium on Signal Processing \& Its Applications (CSPA), Malacca City, 2016, pp. 124-129.

[27] M. K. Uddin, S. Mekhilef, and G. Ramasamy, "Compact wireless IPT system using a modified voltage-fed multiresonant class EF 2 Inverter,” Journal of Power Electron., vol. 18, no. 1, pp. 277-288, 2018. 


\section{BIOGRAPHIES OF AUTHORS}
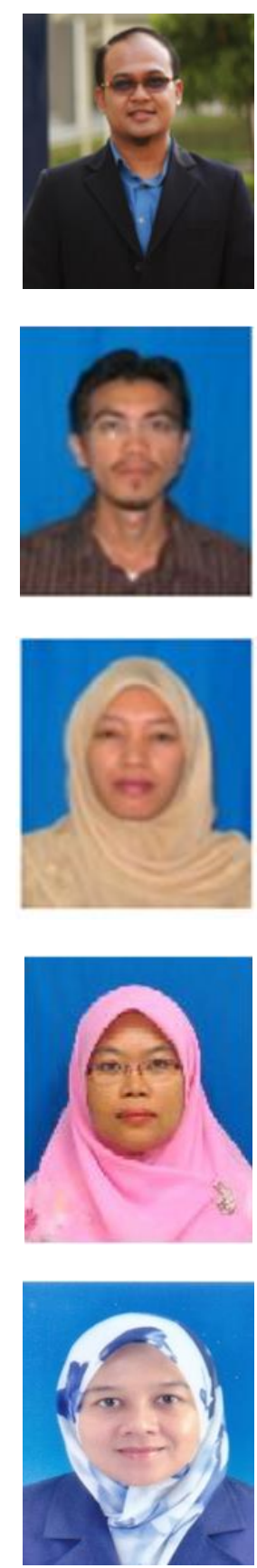

Khairul Kamarudin Bin Hasan Msc (Electronic System), B.Eng (Hons) Electronic Industrial Engineering, Dip. In Electronic Engineering. Mr Khairul is Lecturer at Faculty of Electrical Engineering, Universiti Teknologi Mara, Cawangan Johor, Kampus Pasir Gudang, Johor, Malaysia. He is currently a part time PhD student in Electronic at Universiti Teknikal Malaysia Melaka. His research interest Wireless Power Transfer, Power Electronic, Control system and Drive.

Shakir Saat Ph.D degree Electrical Engineering, Meng (Electrical Engineering), B.Eng (Hons) Electrical Engineering, Dr Shakir Saat is Senior Lecturer at Faculty of Electronic and Computer Engineering, Universiti Teknikal Malaysia, Melaka, Malaysia. He completely in $\mathrm{Ph} . \mathrm{D}$. degree in electrical engineering (Nonlinear Control Theory) from the University of Auckland, New Zealand, in 2013. His current research interests include nonlinear control theory, polynomial discrete-time systems, networked control systems, and wireless power transfer technologies

Yusmarnita Yusof Ph.D degree Electronic Engineering ,M.Eng (Electtrical Engineering), B.Eng(Hons ) Electrical Engineering, Mrs Yusmarnita is Senior Lecturer at Faculty of Electronic and Computer Engineering, Universiti Teknikal Malaysia, Melaka, Malaysia.. Her area of research interests include electronic system design, wireless power transfer and power electronics.

Huzaimah Husin M. Eng. Degree, B.Eng. degree She was appointed Engineering Instructor (2001) at Kolej Universiti Teknikal Malaysia Melaka and promoted to Lecturer (2005) and Senior Lecturer (2008) in the Department of Industrial Electronics, Faculty of Electronic and Computer Engineering at Universiti Teknikal Malaysia Melaka. Since September 2014, she has been pursuing her Ph.D. degree in Advanced Control Technology with a focus on acoustics energy transfer.

Nor Diyana Md Sin PhD in Electrical Engineering (Nanoelectronics), degree in in Electrical Engineering with honors. Lecturer in the Faculty of Electrical Engineering of the Universiti Teknologi MARA (UiTM), Malaysia. Her research interest are in the area of sensor, metal oxide semiconductors, nanotechnology and nanodevices. 